\title{
Behavioral complexity of British gambling advertising
}

Philip W. S. Newall, University of Stirling

Accepted for publication in Addiction Research \& Theory, published by Taylor and

Francis: $\underline{\text { https://doi.org/10.1080/16066359.2017.1287901 }}$

Background: The scale and complexity of British gambling advertising has increased in recent years. "Live-odds" TV gambling adverts broadcast the odds on very specific, complex, gambles during sporting events (e.g., in soccer, "Wayne Rooney to score the first goal, 5-to-1," or, "Chelsea to win 2-1, 10-to1"). These gambles were analyzed from a behavioral scientific perspective (the intersection of economics and psychology). Method: A mixed methods design combining observational and experimental data. A content analysis showed that live-odds adverts from two months of televised English Premier League matches were biased towards complex, rather than simple, gambles. Complex gambles were also associated with high bookmaker profit margins. A series of experiments then quantified the rationality of participants' forecasts across key gambles from the content analysis (Total $N=1,467$ participants across 5 Experiments). Results: Soccer fans rarely formed rational probability judgments for the complex events dominating gambling advertising, but were much better at estimating simple events. Conclusions: British gambling advertising is concentrated on the complex products that mislead consumers the most. Behavioral scientific findings are relevant to the active public debate about gambling.

Keywords: sports betting; in-play gambling; television advertising; behavioral science; behavioral science of gambling; economics; psychology

\section{Introduction}

Gambling is an active British pastime of key economic importance, with the latest figures showing the public’s annual losses are running at $£ 13.6$ billion, or $£ 310$ (\$439) per adult per year (Ellson, 2016). These gambling losses are supported by frequent advertising that stresses the gratification, possibilities, and excitement involved in gambling. The latest figures show that $4.1 \%$ of all TV advertising in 2012 was for 
gambling (Ofcom, 2013), and that the industry has spent $£ 500$ million on advertising since 2012 (Davies, 2016). Newsworthy figures such as these have stoked a heated debate about gambling's role in British society (Bridge, 2016; Sylvester, 2014). This paper adds data to this debate by showing that previous behavioral science (the intersection of economics and psychology) findings conceptually replicate and have regulatory implications for "live-odds" TV gambling adverts. A relatively modern invention, live-odds adverts have become an unavoidable part of watching British sports. Live-odds adverts broadcast odds on specific gambles (e.g., "Wayne Rooney to score the first goal, 5/1") during televised matches. The same advertising also occurs across a diverse range of media, for example betting shop windows, newspapers, online banner adverts and social media, and SMS text messaging.

Research in a range of consumer markets, such as credit cards, mobile phone contracts, and subprime mortgages shows that highly-complex and often poor value-formoney products are often sold to the least-informed consumers (Bar-Gill \& Stone, 2009; Bar-Gill, 2009; Bar-Gill, 2012; Ru \& Schoar, 2016). Less-informed credit card customers are more likely to receive promotions highlighting salient near-term but small benefits, while savvier consumers are more likely to receive promotions with higher long-term rewards (Ru \& Schoar, 2016). Complicated subprime mortgages, which offered low current payments but high deferred costs, were often sold to the leastinformed consumers (Bar-Gill, 2009; Bar-Gill, 2012). Gambling products have also increased in complexity in recent years; consumers can now gamble in more ways than ever before, and gamblers may also be misled by complexity.

Here complexity is defined in relation to sports betting as the number of relevant possible outcomes that could happen in a specific class of events. For example, forecasting a soccer match's end result is relatively "simple" as there are only three 
relevant outcomes (Team A wins, draw, Team B wins, called "three-outcome" gambles here). More "complex" tasks include forecasting the first goalscorer (at least 20 players could score the first goal), or the final match scoreline (an indefinite but large number, e.g., Team A wins 4-3). An economic consideration is that complex soccer gambles have higher bookmaker profit margins than simple gambles (Ayton, 1997; Dixon \& Pope, 2004; Forrest \& Simmons, 2001; Newall, 2015). The bookmaker profit margin can be calculated by summing the implied probabilities from quoted odds for a complete set of events (Kuypers, 2000). ${ }^{1}$ The higher these odds sum to above probability $=1$, the higher the bookmaker profit margin is. For example, a study of bookmaker odds over the 2014 soccer World Cup found average bookmaker profit margins of $4.6 \%$ for simple three-outcome gambles but much higher profit margins for more complex first goalscorer (32.3\%) and scoreline (21.9\%) gambles (Newall, 2015). Complexity also has psychological implications: complex probabilities are frequently overestimated, compared to simpler probabilities, across a range of domains (Fox, Rogers, \& Tversky, 1996; Fox, 1999; Sonnemann, Camerer, Fox, \& Langer, 2013; Tversky \& Koehler, 1994). For example, in the classic demonstration participants estimated a higher probability of "death resulting from heart disease, cancer or some other natural cause" than the logically-equivalent probability of "death from natural causes,” (Tversky \& Koehler, 1994). Making complex sports predictions can also bias latter simple event predictions for the same sporting event (Kelly \& Simmons, 2016). Soccer fans also struggle to estimate complex probabilities involving the joint estimation of multiple soccer matches, although these events do not feature frequently in British gambling advertising (Erceg \& Galić, 2014; Nilsson \& Andersson, 2010;

\footnotetext{
${ }^{1}$ Where bookmaker profit margin $=($ sum of probabilities -1$) /$ sum of probabilities
} 
Teigen, Martinussen, \& Lund, 1996). However, the previous findings in other domains would suggest that soccer fans may for example think that Team A has a higher probability of winning when that judgment is elicited by thinking about individual Team A winning scorelines and summing them, than compared to directly estimating Team A's chances of winning. If confirmed, this would give a psychological reason for the economic pattern that complex soccer gambles are associated with high bookmaker profit margins, and suggest that consumers tend to overestimate the winning chances of complex soccer gambles. This would have implications for the regulation of gambling advertising, given the high frequency with which complex gambles occur in British soccer gambling advertising (Newall, 2015).

The behavioral scientific approach taken here aims to complement other perspectives on gambling advertising (Binde, 2014). Problem gambling is increasingly viewed as a public health issue (Adams, 2008; Ferentzy \& Turner, 2013; Grinols, 2004; Orford, 2010). The critical social marketing perspective acknowledges that gambling firms' marketing strategies are likely to be harmful to the end consumer (Moodie \& Hastings, 2009).

The current focus on soccer sports betting is complementary to findings in other gambling forms. Las Vegas-based electronic gaming machines exploit various decisionmaking errors (Schüll, 2012). Lottery players are for example often categorized as irrational (Ariyabuddhiphongs, 2011), or as having a consumption value of playing (McCaffrey, 1994), and are motivated by wanting to improve their socioeconomic position (Haisley, Mostafa, \& Loewenstein, 2008).

Downstream negative consequences of gambling include increased risk of suicide (Black et al., 2015; Suissa, 2011). It has been suggests that gambling fills the void left by tobacco advertising in sports (Turco, 1999). But public attitudes towards 
sports gambling are rapidly shifting (Claussen \& Miller, 2001). Gambling advertising increases public acceptance of gambling (Parke, Harris, Parke, Rigbye, \& Blaszczynski, 2015). Gambling advertising around sporting events helps to normalize gambling amongst children and adolescents (Hing, Vitartas, Lamont, \& Fink, 2014), and gambling adverts prompt a large percentage of young people to gamble (J. Derevensky, Sklar, Gupta, \& Messerlian, 2010). Youth gambling is arguably an important "hidden addiction" (J. L. Derevensky, Shek, \& Merrick, 2011). Negative consequences of gambling are likely to be heightened if gambling advertising is systematically focused on gambles, with high average losses but which consumers incorrectly overestimate, as claimed here.

\section{Method}

A mixed methods design was used to combine observational data on gambling adverts that British soccer fans see, with experimental data on the rationality of soccer fans' forecasts for commonly advertised gambles from the observational study.

\section{TV adverts observational study}

Live-odds gambling adverts were recorded during all televised English Premier League soccer matches over January and February 2016. While gambling adverts are shown during other sports and other soccer matches, the English Premier League is the most high-profile league of the UK's favorite sport. Similar gambling adverts appear in other media, for example in newspapers, online, and in betting shop windows. Given the time required to collect, code, and analyze these data, TV adverts during English Premier League soccer matches were chosen as the highest-impact sub-sample of adverts. Adverts were then coded by gamble type, the odds of the specific gamble, and the bookmaker offering the gamble. In total 63 gambles were recorded over 28 matches $(M$ 
$=2.25$ per-match), across five different bookmakers. Adverts were either shown before the start of the match, or during the half-time break. The Southampton versus West Ham match on February $8^{\text {th }}$ was the only match without any live-odds adverts.

Gambling odds data were downloaded from WilliamHill.com, one of the largest UK bookmakers. Since bookmakers tend to quote similar odds for soccer events (Newall, 2015), it was deemed that one bookmaker's odds would serve as a sufficient proxy for all bookmakers' odds. Full match data were later downloaded from whoscored.com (including the names of specific players taking part). These data were then used to estimate the bookmaker profit margin for various types of advertised gambles.

\section{Experiments}

In each experiment participants gave subjective probabilities for potential events in an upcoming real-life soccer match. Participants always estimated the three probabilities for the simplest three-outcome gambles, and probabilities for at least one more complex type of gamble. Estimates were given one at a time for each type of gamble, before moving onto a new type of gamble. Participants should ideally give a sum of subjective probabilities for a complete class of events equal to probability $=1$. If judgments are on average overconfident, then the sum of subjective probabilities will exceed probability $=1$.

\section{Participants.}

Participants for each experiment were recruited for a short online survey. Participants in Experiments 1-4 were recruited from the online crowdsourcing platforms Prolific Academic or Mechanical Turk (see Table 1). Online crowdsourcing platforms are becoming a popular alternative to undergraduate participant pools, as crowdsourcing 
platforms allow for large samples of demographically-diverse participants to be recruited easily and cost-effectively (Buhrmester, Kwang, \& Gosling, 2011; Paolacci, Chandler, \& Ipeirotis, 2010). Research shows that these online participants are at least as attentive to task instructions as participants from traditional university-based pools (Hauser \& Schwarz, 2016; Ramsey, Thompson, McKenzie, \& Rosenbaum, 2016). Studies of the Mechanical Turk participant pool suggest that its participants are similar to the US population, if slightly younger on average (Huff \& Tingley, 2015). Prolific Academic is a newer crowdsourcing platform than Mechanical Turk, and was used primarily for its ability to recruit UK-based participants (Mechanical Turk users are primarily from the US).

These participants take part in academic experiments from their own homes in return for payment. Participants opt-into taking part with a study after seeing the baseline payment, estimated completion time, average completion time of past participants, and study content. Table 1 shows details of the baseline payments and average hourly payment rate for participants in Experiments 1-4. The average participant in the three Prolific Academic experiments received an average per-hour payment of between $£ 7.50-£ 8.64$. Participants in the Mechanical Turk experiment received an average per-hour payment of $\$ 2.70$, a lower amount, but which is slightly above average for per-hour payment rates on Mechanical Turk (Ross, Irani, Silberman, Zaldivar, \& Tomlinson, 2010).

In Experiments 1-4 participants gave predictions about an upcoming real world soccer match involving their national team. Participants selected into the task after clicking a short descriptive link, e.g., "USA vs. Guatemala soccer match $30^{\text {th }}$ March predictions." However, there is the possibility that some participants may take part for the financial reward even if they have no interest in soccer. To help prevent against this, 
participants provided the number of soccer matches watched (either in-person or on television) during 2015. Participants responding "zero" were excluded from the analysis (see Table 1). In addition, a special group of dedicated soccer fans was recruited via social media for Experiment 5. Fans of the Premier League team Arsenal were recruited via postings on Arsenal-related Reddit pages and Twitter accounts. These participants were highly engaged with soccer, reporting watching an average of 74.5 soccer matches in 2015 (all reported a positive number for number of matches watched in 2015, suggesting that they were indeed soccer fans).

The norm in economic experiments is to have some level of incentive-based pay, in addition to a baseline payment, to incentivize participants to think hard and engage with the task. Random lotteries of various sizes were used to incentivize truthful responses in Experiments 1-4, using an established procedure (Harrison, MartínezCorrea, \& Swarthout, 2014). The chance of winning the lottery depends on both participants' answers and what actually happened in the match. With this procedure participants had a higher weighted chance of winning the lottery if events that they said were likely then actually occurred in the match. Because this procedure uses a complicated non-linear scoring rule to weight participants' probability of winning a prize, participants were just (truthfully) told, "The likelihood of winning a prize depends on both your choices and what actually happens. Providing accurate predictions will maximize your chances of winning."

\section{Materials.}

Participants gave subjective probabilities for events in an upcoming soccer match. It is important to elicit subjective probabilities in a way that participants can understand. As seen for example in Figure 1, live-odds gambling adverts tend to use fractional odds $\mathrm{x} / \mathrm{y}$, where $\mathrm{x}$ represents the potential profit from a successful bet of $\mathrm{y}$ units, 
corresponding to a probability of $\mathrm{y} /(\mathrm{x}+\mathrm{y})($ Cortis, 2015). However, many people are likely to find this method of stating probabilities unintuitive.

An often-observed effect is that people perform better with probabilistic information when probabilities are reframed into natural frequencies involving whole numbers of events (Gigerenzer \& Hoffrage, 1995). For example, "2 out of 100” is easier for many people to incorporate in calculations than "probability $=0.02$." Subsequent work in a soccer estimation task suggests that soccer fans may find it easier to state subjective probabilities about upcoming soccer matches in natural frequencies (Erceg \& Galić, 2014). All participants were presented instructions such as the following (depending on the event types they were estimating):

Imagine that the match will be played 100 times. Your task is to predict how many times the match will end in a stated outcome.

For example:

"England to win"

In how many of the 100 matches would England win the match?

Please answer with a whole number between 0 and 100 , where 0 means that the match will never end in that stated outcome, and 100 means the match will always end in that stated outcome.

\section{Procedure.}

Participants opted-into the survey by clicking a link on the participant pool website. Participants then read and agreed to a consent form before continuing to the online experiment. Participants gave subjective probabilities for one outcome at a time in a given event type by typing a number between zero and 100. Participants did this for each outcome in an event type (e.g., three estimates for a three-outcome gamble), before moving onto a new event type. Event type order was randomized. First goalscorer 
events used the predicted line-up on whoscored.com (since the experiment was performed before the date of the match, the exact line-ups were not known at the time of the experiment). At the end of the experiment participants were given a confirmation code which allowed them to claim payment for the survey from the participant pool website. Full experimental instructions as seen by participants and results can be downloaded from https://osf.io/68mzv/.

\section{Measures.}

The main dependent variable was the sum of probability judgments for a complete set of events (e.g., Team A wins, draw, Team B wins). Rational probability judgments are "coherent," summing to probability = 1 for a complete set of events. "Incoherent" beliefs sum to greater than probability $=1$, and can result in decision makers accepting guaranteed losing sequences of gambles (Seidenfeld, 1985). For example, if someone has probability beliefs summing to probability 1.5 , while a bookmaker quotes odds for the same events summing to a total of 1.4 , then the person will think at least one event is more likely than implied by the bookmaker's price, and may well find that gamble attractive. The higher a person's sum of probability judgments above probability $=1$, the less rational they are as measured by this standard.

At the end of each experiment, participants entered the number of live soccer matches (on TV or in person) that they watched in 2015. Participants responding "zero" were excluded from the following analysis.

\section{Results}

Table 2 shows results of the content analysis from the observational study (full details can be downloaded from https://osf.io/68mzv/). Each live-odds gambling advert was broken down into specific types of gambles that can be made on a soccer match. Three- 
outcome gambles were advertised $17.5 \%$ of the time, and were always advertised as a "new customer enhanced price" - offering unusually high potential wins for these gambles as a potential reward to new customers only. All other advertised gambles were more complex. The third column in Table 2 shows the "mean decimal odds" for each gamble type. The decimal odds represent the total win from a successful bet of $\$ 1 / £ 1$. As can be seen, complex gambles offer high potential wins, and are potentially alluring to gamblers who are attracted by the maximum potential win (Golec \& Tamarkin, 1998).

The majority of advertised gambles involved a player scoring a goal (58.7\%), which involves a number of complex comparisons given the 20 outfield players taking part in a soccer match. Usually the advertised gamble was on the identity of the first/next goalscorer (39.7\%). The other cases involved complex combinations of events, such as a player scoring and their team winning (12.7\%), or a gamble on two specific players each scoring (3.2\%). Other advertised gambles were on the correct scoreline $(6.3 \%)$, or on a team to win and both teams to score $(17.5 \%$, otherwise known as a "six-outcome" gamble, as teams either will or won't both score). Other than the $17.5 \%$ of three-outcome gambles, the remaining advertised gambles involved complex events. These results are similar to a past observational study of gambling advertising during the 2014 World Cup (Newall, 2015). Panel a in Figure 1 shows screenshots of examples of commonly advertised gambles.

Were the odds on advertised complex gambles fair? There were 37 adverts involving a player scoring a goal. Gambling odds data downloaded from WilliamHill.com and player information from whoscored.com can be used to give a rough estimate for these adverts. In total 20 outfield players start each match, either one of these players will score the first goal or no goal will be scored. These 21 probabilities 
should add up to probability $=1$ if the odds are fair (in fact, less than one given that a substitute player may score the first goal). Actually, the probabilities added up to an average of 1.529 , resulting in a bookmaker profit margin of $34.6 \%$. By contrast, odds for three-outcome gambles for these games added up to an average of 1.060, resulting in a much lower bookmaker profit margin of 5.7\%. The cost of complexity was not limited to first goalscorer gambles: odds on the four advertised scoreline gambles added to an average of 1.301 , or a bookmaker profit margin of $23.2 \%$. While this is only a small sample, the previous literature repeatedly also finds that gamble complexity and bookmaker profit margins are positively correlated (Ayton, 1997; Dixon \& Pope, 2004; Forrest \& Simmons, 2001; Newall, 2015).

Panel $b$ of Figure 1 shows the experimental results. Results were remarkably consistent across all participant groups, suggesting that differences in participant payment and recruitment did not affect the experimental results. Panel $b$ shows that three-outcome gambles were estimated the closest to probability $=1$ across all experiments (or equivalently as 100 percent as these judgments were actually elicited from participants). Mean three-outcome estimates ranged in a narrow band from 103.3 percent (Experiment 1) to 111.6 percent (Experiment 4). This demonstrates that average responses were not overconfident when the event being asked about was sufficiently simple (across all participant groups). The other more complex gambles were estimated less accurately. Six-outcome gambles (17.5\% of advertised gambles) break each event in a three-outcome gamble into two possibilities: Either both teams score (see e.g., topright of Panel a, "Liverpool to win and both teams to score"), or at least one team fails to score. Even this relatively minor doubling of possible outcomes led to large increases in summed probability judgments in Experiments $3(M=150.7))$ and $4(M=166.7)$ (Panel b). 
Scoreline gambles, e.g., Team A to win 1-0, 2-0, 2-1 etc., are sub-cases of the three-outcome gamble "Team A to win." (6.3\% of advertised gambles, see bottom-right of Panel a). The large number of potential scorelines leads to additional complexity compared to three-outcome gambles. Probabilities were elicited for the 16 most likely scorelines (every scoreline from 0-0 to 3-3). Scoreline judgments summed to an average of 279.0 percent (Experiment 2) and 306.4 percent (Experiment 4).

The remaining $58.7 \%$ of advertised gambles involved specific players scoring a goal (see bottom-left of Panel a). These gambles are complex. There are for example 20 outfield players who could score the first goal (plus the probability that nobody scores). Participants in Experiment 1 gave mean responses for these 21 probabilities of 248.8 percent. These were the same participants who nonetheless provided highly accurate three-outcome forecasts. Participants in Experiments 1-4 were recruited from online crowdsourcing websites. It could be that dedicated fans will give more accurate responses. Fans of the English Premier League team Arsenal were recruited from social media for Experiment 5. These fans estimated the probability of the 10 Arsenal players scoring the first goal and the probability of no-goal. Their responses summed to an average of 124.5 percent, before even considering the possibility of the rival team scoring (they only estimated 11 of 21 possible events to minimize the burden of this unpaid survey; eliciting preferences over the full 21 events may well have produced very similar results to those found in Experiment 1). Their first goalscorer estimates were significant higher than their three-outcome estimates $(t(212)=-3.27, p=.001)$.

\section{Discussion}

This paper illustrates economic and psychological (and hence behavioral scientific) factors relevant to British gambling advertising. A content analysis of high-impact televised soccer adverts showed that most advertised gambles were for complex events. 
Gamble complexity is economically-relevant, given the high bookmaker profit margins for complex events shown here and elsewhere. The series of five experiments in this paper then demonstrated the psychological relevance of gamble complexity, showing the over-optimistic probabilistic expectations surrounding complex events, conceptually replicating experimental evidence in other domains. These complimentary streams of economic and psychological evidence suggest that consumers require additional help to accurately understand the complex events involved in British gambling advertising.

Future research should aim to address the limitations of the data presented in this paper. The content analysis was performed over a relatively small number of adverts. While the types of advertised gambles closely followed a previous study of bookmaker window and TV adverts (Newall, 2015), the prevalence of similar gambling advertising over a wide variety of media suggest the scope for a wider follow-up study (e.g., across betting shop windows, newspapers, online banner adverts and social media, and SMS text messaging). Research should also investigate similar gambling advertising across other sports and in other countries (Hing, Sproston, Brook, \& Brading, 2016).

Future research should also address any potential limitations in this paper's experimental evidence. While event complexity led to increasingly over-optimistic beliefs across both general population and soccer fan samples, this may possibly be an artefact of the experimental situation. It is possible that behavior will differ when participants must risk their own money with each prediction, as when gambling. It could also be the case that experienced gamblers display different behaviour than nonexperienced gamblers. Research in other domains does show, however, that complex probabilities are overestimated compared to simple probabilities even in highly incentivized and repeated laboratory and real world tasks (Sonnemann et al., 2013). 
This evidence is relevant to gambling advertising regulatory policy. Consumers' inability to accurately understand complex events suggests that these adverts should at a minimum be combined with some sort of disclosure highlighting the long-run risks of advertised gambles. Prominently disclosing the relevant bookmaker profit margin alongside any advertising should help consumers to appreciate the long-run risks of advertised gambles. While there has been a large public response to the risks of gambling on "fixed odds betting terminals (FOBTs)" (Bridge, 2016), many consumers may be unaware that the maximum bookmaker profit margin of 3\% on FOBTs (Europe Economics, 2005) is much lower than bookmaker profit margins on complex soccer gambles.

Disclosing bookmaker profit margins is similar to recommendations for helping consumers navigate complexity in other consumer markets (Bar-Gill, 2012). If successful, this strategy may help consumers to either avoid or be more price-sensitive with costly complex gambles. This is similar to calorie information disclosure for food, or alcohol content disclosure, which aim to alert consumers to relevant risks across different products. However, any education campaign around the risks of gambling products must be aware of research highlighting the fundamental difficulties much of the population faces with evaluating statistical risks and processing numerical information (Gigerenzer, 2002; Kahneman, 2011). Disclosure of relevant bookmaker profit margins would be a welcome addition to recent industry-led changes around gambling advertising (Senet Group, 2014).

As of August 2016 Britain's highest-circulation newspaper, The Sun, has opened its own bookmaker, "The Sun Bets." This new bookmaker is being actively crosspromoted in The Sun. Importantly, this bookmaker does not just offer bets on sporting events, but on a range of events likely to appeal to a much wider part of the population. 
For example, on the $31^{\text {st }}$ of August and $1^{\text {st }}$ of September 2016, The Sun newspaper ran features discussing the betting odds of the next actor to play James Bond and the next winner of the BBC's Strictly Come Dancing (a full double page spread in the latter case). Quoted odds implied a bookmaker profit margin of $10.4 \%$ for James Bond (6 potential events) and a profit margin of $20.3 \%$ for Strictly Come Dancing (15 potential events). This again helps to illustrate the link between the bookmaker profit margin and event complexity. Few consumers are likely to appreciate these differential risks, and hence disclosures should accompany this form of gambling advertising. It is not just sports-watching consumers who are now exposed to this form of gambling advertising.

\section{Conclusions}

The easy availability of gambling and the prominence of gambling advertising have led to an active public debate in Britain (Bridge, 2016; Sylvester, 2014). Numerous public health consequences of gambling are possibly worsened when gamblers are losing more money than they can afford (Adams, 2008; Ferentzy \& Turner, 2013; Grinols, 2004; Orford, 2010). The costs of gambling are high, with the most recent figures indicating average losses of $£ 310$ per adult per year (Ellson, 2016). This research highlights how a relevant psychological factor, event complexity, may lead to consumers underestimating the costs of complex gambles with high bookmaker profit margins. Only educated and informed consumers, who fully understand the relevant risks of different gambling products, can gamble responsibly.

\section{Acknowledgements}

This research was funded by an early career engagement grant from the Scottish Institute for Research in Economics. Thanks to Anam Hassan and Lucia Newall for help with data collection. Thanks to David Comerford, Nathan Critchlow, Eimear Crowe, and Liam Delaney for their many helpful suggestions. 


\section{Declaration of interest}

The author reports no conflicts of interest. The author alone is responsible for the content and writing of this article.

\section{References}

Adams, P. J. (2008). Gambling, freedom and democracy. New York: Routledge.

Ariyabuddhiphongs, V. (2011). Lottery gambling: A review. Journal of Gambling Studies, 27(1), 15-33.

Ayton, P. (1997). How to be incoherent and seductive: Bookmakers' odds and support theory. Organizational Behavior and Human Decision Processes, 72(1), 99-115.

Bar-Gill, O. (2009). The law, economics and psychology of subprime mortgage contracts. Cornell Law Review, 94(5), 1073-1151.

Bar-Gill, O. (2012). Seduction by contract: Law, economics, and psychology in consumer markets. Oxford: Oxford University Press.

Bar-Gill, O., \& Stone, R. (2009). Mobile misperceptions. Harvard Journal of Law \& Technology, 23(1), 49-118.

Binde, P. (2014). Gambling advertising: A critical research review. London: Responsible Gambling Trust.

Black, D. W., Coryell, W., Crowe, R., McCormick, B., Shaw, M., \& Allen, J. (2015). Suicide ideations, suicide attempts, and completed suicide in persons with 
pathological gambling and their First- Degree relatives. Suicide and LifeThreatening Behavior, 45(6), 700-709.

Bridge, S. (2016). Calls for the government to slash the maximum stake size on fixedodds betting machines from $£ 100$ a spin to $£ 2$. Retrieved from http://www.thisismoney.co.uk/money/news/article-3705673/Calls-Governmentslash-maximum-stake-size-betting-machines-100-spin-2.html

Buhrmester, M., Kwang, T., \& Gosling, S. D. (2011). Amazon's mechanical turk a new source of inexpensive, yet high-quality, data? Perspectives on Psychological Science, 6(1), 3-5.

Claussen, C. L., \& Miller, L. K. (2001). The gambling industry and sports gambling: A stake in the game? Journal of Sport Management, 15(4), 350-363.

Cortis, D. (2015). Expected values and variances in bookmaker payouts: A theoretical approach towards setting limits on odds. The Journal of Prediction Markets, 9(1), $1-14$.

Davies, R. (2016). Betting firms spent half a billion pounds on TV adverts since 2012. Retrieved from https://www.theguardian.com/society/2016/jul/15/betting-firmsspent-half-a-billion-pounds-on-tv-adverts-since-2012

Derevensky, J. L., Shek, D., \& Merrick, J. (Eds.). (2011). Youth gambling: The hidden addiction. Berlin: De Gruyter.

Derevensky, J., Sklar, A., Gupta, R., \& Messerlian, C. (2010). An empirical study examining the impact of gambling advertisements on adolescent gambling attitudes and behaviors. International Journal of Mental Health and Addiction, 8(1), 21-34. 
Dixon, M. J., \& Pope, P. F. (2004). The value of statistical forecasts in the UK association football betting market. International Journal of Forecasting, 20(4), $697-711$.

Ellson, A. (2016). Punters lose $£ 14$ bn as online bets fuel gambling epidemic. Retrieved from http://www.thetimes.co.uk/article/punters-lose-14bn-as-online-bets-fuelgambling-epidemic-2919hl30v

Erceg, N., \& Galić, Z. (2014). Overconfidence bias and conjunction fallacy in predicting outcomes of football matches. Journal of Economic Psychology, 42, 52 62.

Europe Economics. (2005). Fixed odds betting terminals and the code of practice: A report for the association of british bookmakers limited. Retrieved from http://www.europe-economics.com/publications/abbl_2006.pdf

Ferentzy, P., \& Turner, N. E. (2013). A history of problem gambling. New York: Springer.

Forrest, D., \& Simmons, R. (2001). Globalisation and efficiency in the fixed-odds soccer betting market. Unpublished manuscript.

Fox, C. R. (1999). Strength of evidence, judged probability, and choice under uncertainty. Cognitive Psychology, 38(1), 167-189.

Fox, C. R., Rogers, B. A., \& Tversky, A. (1996). Options traders exhibit subadditive decision weights. Journal of Risk and Uncertainty, 13(1), 5-17. 
Gigerenzer, G. (2002). Calculated risks: How to know when numbers deceive you. New York: Simon and Schuster.

Gigerenzer, G., \& Hoffrage, U. (1995). How to improve bayesian reasoning without instruction: Frequency formats. Psychological Review, 102(4), 684-704.

Golec, J., \& Tamarkin, M. (1998). Bettors love skewness, not risk, at the horse track. Journal of Political Economy, 106(1), 205-225.

Grinols, E. L. (2004). Gambling in america: Costs and benefits. New York: Cambridge University Press.

Haisley, E., Mostafa, R., \& Loewenstein, G. (2008). Subjective relative income and lottery ticket purchases. Journal of Behavioral Decision Making, 21(3), 283-295.

Harrison, G. W., Martínez-Correa, J., \& Swarthout, J. T. (2014). Eliciting subjective probabilities with binary lotteries. Journal of Economic Behavior \& Organization, $101,128-140$.

Hauser, D. J., \& Schwarz, N. (2016). Attentive turkers: MTurk participants perform better on online attention checks than do subject pool participants. Behavior Research Methods, 48(1), 400-407.

Hing, N., Vitartas, P., Lamont, M., \& Fink, E. (2014). Adolescent exposure to gambling promotions during televised sport: An exploratory study of links with gambling intentions. International Gambling Studies, 14(3), 374-393. 
Hing, N., Sproston, K., Brook, K., \& Brading, R. (2016). The structural features of sports and race betting inducements: Issues for harm minimisation and consumer protection. Journal of Gambling Studies, doi:10.1007/s10899-016-9642-6

Huff, C., \& Tingley, D. (2015). "Who are these people?” evaluating the demographic characteristics and political preferences of MTurk survey respondents. Research \& Politics, 2(3), 1-12.

Kahneman, D. (2011). Thinking, fast and slow. New York: Macmillan.

Kelly, T. F., \& Simmons, J. P. (2016). When does making detailed predictions make predictions worse? Journal of Experimental Psychology: General, 145(10), 12981311.

Kuypers, T. (2000). Information and efficiency: An empirical study of a fixed odds betting market. Applied Economics, 32(11), 1353-1363.

McCaffrey, E. J. (1994). Why people play lotteries and why it matters. Wisconsin Law Review, 71(1), 71-122.

Moodie, C., \& Hastings, G. (2009). Social marketing and problem gambling: A critical perspective. Addiction, 104(5), 692-693.

Newall, P. W. S. (2015). How bookies make your money. Judgment and Decision Making, 10(3), 225-231.

Nilsson, H., \& Andersson, P. (2010). Making the seemingly impossible appear possible: Effects of conjunction fallacies in evaluations of bets on football games. Journal of Economic Psychology, 31(2), 172-180. 
Ofcom. (2013). Trends in advertising activity - gambling. Retrieved from http://stakeholders.ofcom.org.uk/binaries/research/tvresearch/Trends_in_Ad_Activity_Gambling.pdf

Orford, J. (2010). An unsafe bet?: The dangerous rise of gambling and the debate we should be having. Singapore: John Wiley \& Sons.

Paolacci, G., Chandler, J., \& Ipeirotis, P. G. (2010). Running experiments on amazon mechanical turk. Judgment and Decision Making, 5(5), 411-419.

Parke, A., Harris, A., Parke, J., Rigbye, J., \& Blaszczynski, A. (2015). Responsible marketing and advertising in gambling: A critical review. The Journal of Gambling Business and Economics, 8(3), 21-35.

Ramsey, S. R., Thompson, K. L., McKenzie, M., \& Rosenbaum, A. (2016). Psychological research in the internet age: The quality of web-based data. Computers in Human Behavior, 58, 354-360.

Ross, J., Irani, L., Silberman, M. S., Zaldivar, A., \& Tomlinson, B. (2010). Who are the crowdworkers?: Shifting demographics in mechanical turk. CHI EA '10: Proceedings of the 28th of the International Conference Extended Abstracts on Human Factors in Computing Systems, New York, NY, USA. 2863-2872.

Ru, H., \& Schoar, A. (2016). Do credit card companies screen for behavioral biases? (working paper no. w22360). Retrieved from http://aschoar.mit.edu/wpcontent/uploads/2016/07/Do-Credit-Card-Companies-Screen-for-BehavioralBiases.pdf 
Schüll, N. D. (2012). Addiction by design: Machine gambling in las vegas. Princeton, NJ: Princeton University Press.

Senet Group. (2014). Gambling industry responds to public concerns. Retrieved from http://senetgroup.org.uk/gambling-industry-responds-to-public-concerns/

Sonnemann, U., Camerer, C. F., Fox, C. R., \& Langer, T. (2013). How psychological framing affects economic market prices in the lab and field. Proceedings of the National Academy of Sciences of the United States of America, 110(29), 1177911784.

Suissa, A. J. (2011). Vulnerability and gambling addiction: Psychosocial benchmarks and avenues for intervention. International Journal of Mental Health and Addiction, 9(1), 12-23.

Sylvester, R. (2014). Stop bombarding our kids with betting ads. Retrieved from http://www.thetimes.co.uk/tto/opinion/columnists/article4160166.ece

Teigen, K. H., Martinussen, M., \& Lund, T. (1996). Linda versus world cup: Conjunctive probabilities in three-event fictional and real-life predictions. Journal of Behavioral Decision Making, 9(2), 77-93.

Turco, D. M. (1999). The state of tobacco sponsorship in sport. Sport Marketing Quarterly, 8(1), 35-38.

Tversky, A., \& Koehler, D. J. (1994). Support theory: A nonextensional representation of subjective probability. Psychological Review, 101(4), 547-567. 
Table 1. Overview of experiments.

\begin{tabular}{|c|c|c|c|c|c|c|c|}
\hline Experiment & Match & $\begin{array}{l}\text { Participant } \\
\text { pool }\end{array}$ & $\begin{array}{l}N \\
\text { Particip } \\
\text { ants } \\
\text { included }\end{array}$ & $\begin{array}{l}N \\
\text { Participan } \\
\text { ts } \\
\text { excluded }\end{array}$ & $\begin{array}{l}\text { Baseline } \\
\text { payment }\end{array}$ & $\begin{array}{l}\text { Average } \\
\text { payment per } \\
\text { hour }\end{array}$ & Incentivization \\
\hline 1 & $\begin{array}{l}\text { Germany vs. } \\
\text { England } 26 \\
\text { March } 2016\end{array}$ & $\begin{array}{l}\text { Prolific } \\
\text { academic } \\
(\mathrm{UK})\end{array}$ & 314 & 85 & $£ 1$ & $£ 7.50 /$ hour & $\begin{array}{l}2 £ 100 \\
\text { bonuses }\end{array}$ \\
\hline 2 & $\begin{array}{l}\text { USA vs. } \\
\text { Guatemala } \\
31 \text { March } \\
2016\end{array}$ & $\begin{array}{l}\text { Prolific } \\
\text { academic } \\
\text { (US) }\end{array}$ & 320 & 75 & $\begin{array}{l}\$ 1 \\
(£ 0.72)\end{array}$ & $\begin{array}{l}\$ 12 / \text { hour } \\
\text { (£8.64/hour) }\end{array}$ & $\$ 100$ bonus \\
\hline 3 & $\begin{array}{l}\text { USA vs. } \\
\text { Guatemala } \\
31 \text { March } \\
2016\end{array}$ & $\begin{array}{l}\text { Mechanical } \\
\text { turk (US) }\end{array}$ & 306 & 95 & $\$ 0.25$ & $\$ 2.70 /$ hour & $\$ 20$ bonus \\
\hline 4 & $\begin{array}{l}\text { England vs. } \\
\text { The } \\
\text { Netherlands } \\
29 \text { March } \\
2016\end{array}$ & $\begin{array}{l}\text { Prolific } \\
\text { academic } \\
(\mathrm{UK})\end{array}$ & 313 & 91 & $£ 1$ & $£ 8.58 /$ hour & $\begin{array}{l}2 £ 100 \\
\text { bonuses }\end{array}$ \\
\hline 5 & $\begin{array}{l}\text { Arsenal vs. } \\
\text { Watford } 2 \\
\text { April } 2016\end{array}$ & $\begin{array}{l}\text { General } \\
\text { public }\end{array}$ & 214 & 0 & -- & -- & -- \\
\hline
\end{tabular}

Note. Bonuses in Experiment 4 were assigned randomly due to a programming error.

No bonus was offered in Experiment 5 to maintain participant anonymity. Participants

who responded that they watched no soccer matches in 2015 were excluded from the analysis. 
Table 2. Observational data on advertised live-odds adverts. The mean decimal odds represent the average potential win from a successful gamble of $£ 1 / \$ 1$ (e.g., decimal odds of 12.0 represent a total payout of $\$ 12$ ).

Gamble type

Number of adverts Mean decimal odds

Three-outcome gamble, new player bonus

$11(17.5 \%)$

8.5

Correct scoreline

$4(6.3 \%)$

12.0

Team A to win and both teams to score (six- $11(17.5 \%)$

outcome gamble)

Player A to score first/next

$25(39.7 \%)$

8.2

Player A to score and Team A to win

$8(12.7 \%)$

5.1

Player A to score and Player B to score

$2(3.2 \%)$

Player A to score a goal

$1(1.6 \%)$

6

Player A to score two or more goals

$1(1.6 \%)$

4.5

Total

63 


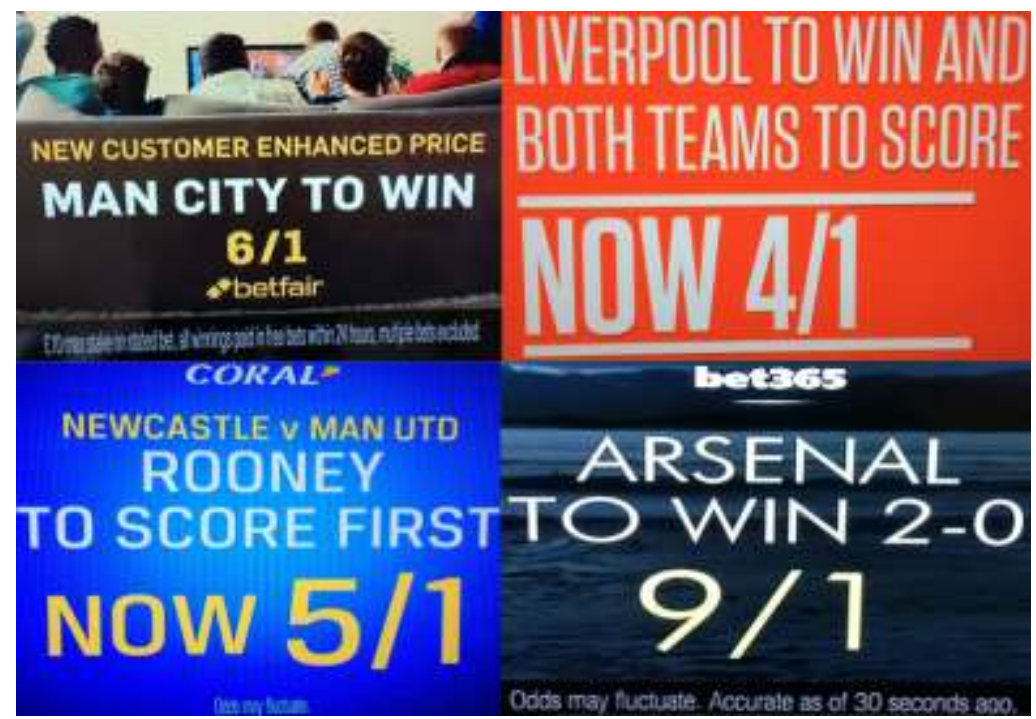

$\mathrm{b}$

Percentage sum

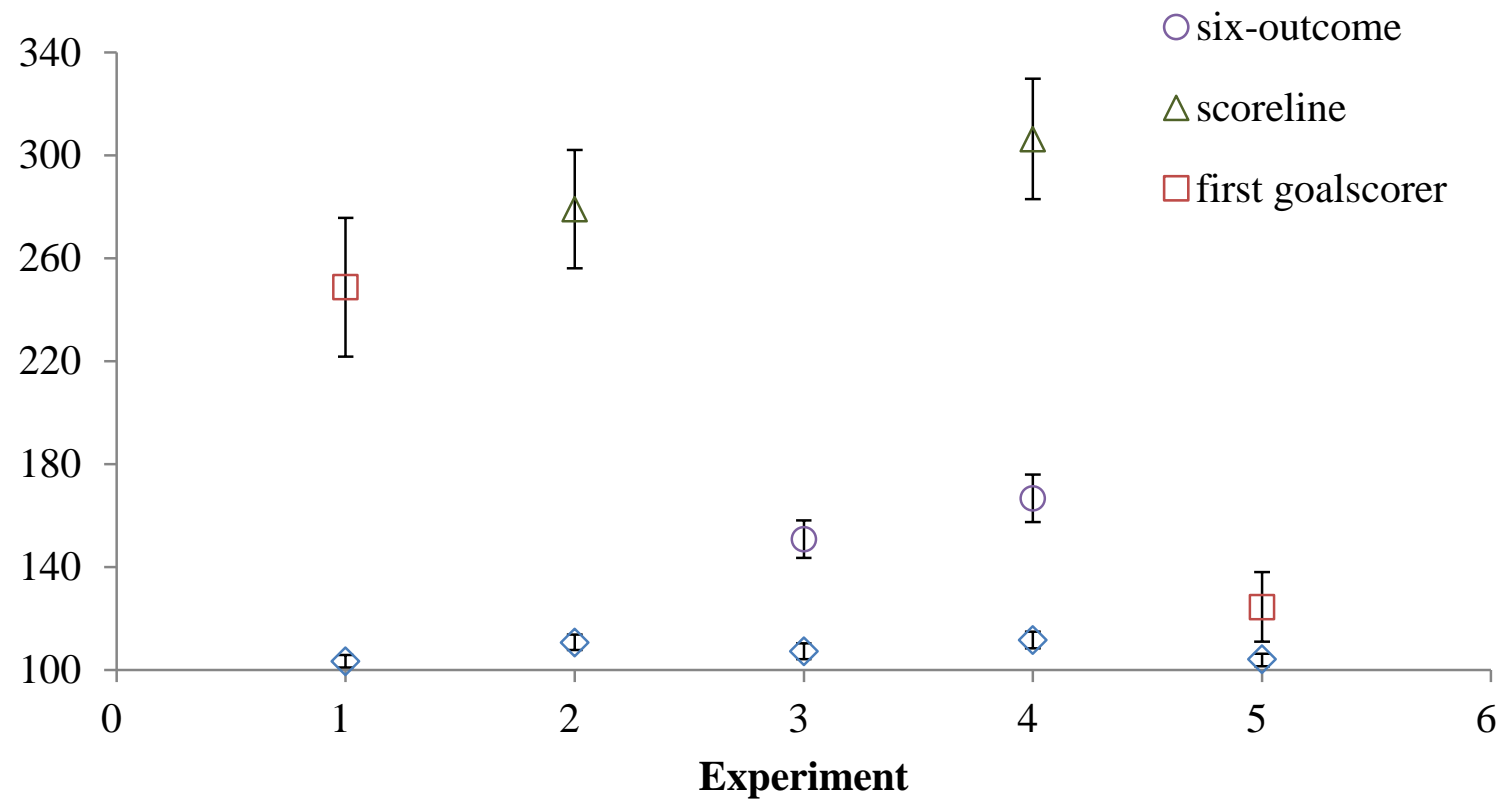

Figure 1. TV advert examples (Panel a) and experimental results (Panel b). Odds of 6/1 mean a winning gamble earns 6 units profit for every 1 unit wagered. Panel a shows examples (clockwise from top-left) of three-outcome, six-outcome, scoreline, and first goalscorer gambles. Error bars are 95\% CIs. There is a clear trend where event complexity, as measured by the number of potential outcomes, drives an increasingly 
judgment sum. First goalscorer estimates in Experiment 5 were elicited over only 11 out of 21 potential events. 